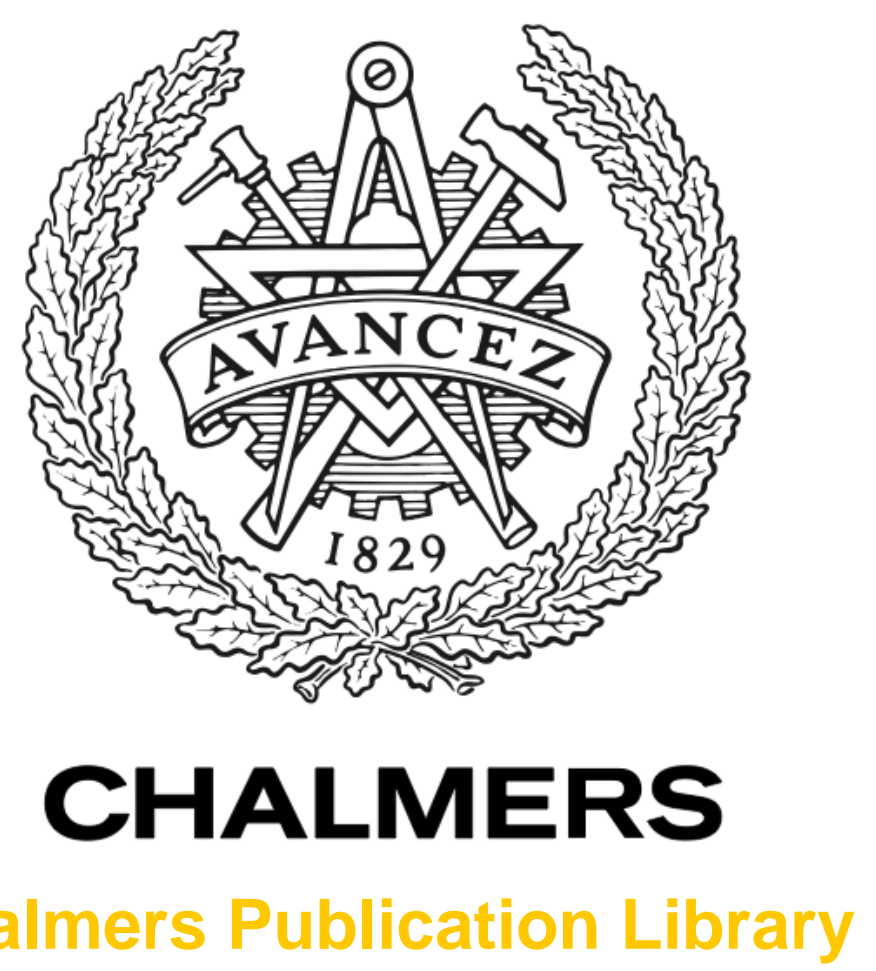

\title{
Frequency Support by Wind Farms in Islanded Power Systems with High Wind Power Penetration
}

This document has been downloaded from Chalmers Publication Library (CPL). It is the author's version of a work that was accepted for publication in:

\section{IEEE POWERTECH 2013}

Citation for the published paper:

Persson, M. ; Chen, P. ; Carlson, O. (2013) "Frequency Support by Wind Farms in Islanded Power Systems with High Wind Power Penetration". IEEE POWERTECH 2013 pp. Art. no. $6652361)$.

http://dx.doi.org/10.1109/PTC.2013.6652361

Downloaded from: http://publications.lib.chalmers.se/publication/179186

Notice: Changes introduced as a result of publishing processes such as copy-editing and formatting may not be reflected in this document. For a definitive version of this work, please refer to the published source. Please note that access to the published version might require a subscription. 


\title{
Frequency Support by Wind Farms in Islanded Power Systems with High Wind Power Penetration
}

\author{
Mattias Persson \\ Peiyuan Chen, Ola Carlson \\ Electric Power Engineering \\ Chalmers University of Technology \\ Gothenburg \\ mattias.persson@chalmers.se
}

\begin{abstract}
The purpose of this paper is to investigate the frequency support in low inertia systems that could be provided by a wind farm during load mismatch. Temporary instant inertia support and inertia emulation support are evaluated and compared. An improved control strategy is presented giving quick power delivery even during low wind speeds. The proposed model can support a loss of generation of $0.1 \mathrm{pu}$ with a wind power penetration of $20 \%$ without violating the $49 \mathrm{~Hz}$ limit. The paper presents this as a solution to allow wind turbines to act on frequency deviations in the fast manner before other production units has caught up and started to produce in accordance to the new power level required. The temporary frequency drop for a wind penetration of $50 \%$ was improved from $47.33 \mathrm{~Hz}$, for the uncontrolled case, to $49.10 \mathrm{~Hz}$ utilizing the suggested adaption of inertia support.
\end{abstract}

Index Terms-- Frequency response, Frequency control, Large scale integration, Power system simulation, Wind power generation, Inertia emulation, Island operation.

\section{INTRODUCTION}

In order to reduce $\mathrm{CO} 2$ emission there is a growing demand for renewable power generation. One of the main renewable energy sources is wind power. Due to wind variability and predictability, the occurrence of load mismatch in the system might increase. With a growing wind power penetration in the grid there is an increasing need for regulation from variable speed wind turbines (VSWTs) to provide support in the form of spinning reserve and for reducing frequency instabilities in the grid. This need originates from the lack of inertia response provided by VSWT in their basic configuration [1]. An increase in wind power penetration ratio (WPR) causes a decrease in total system inertia. These factors result in an increased frequency variation and instability issues in the power system.

An overview of recent grid codes is presented in [9] related to wind power integration. Countries included are Denmark, Germany, Spain, United Kingdome, Ireland, United States and China. It is stated that the UK grid code was the strictest among the investigated related to frequency deviations, requiring a frequency span of $47.5<\mathrm{f}<52 \mathrm{~Hz}$. In

Financial support from Chalmers Energy Initiative is greatly appreciated. contrast, E.ON's (Germany) grid code is the least strict, allowing a frequency span of $46.5<\mathrm{f}<53.5 \mathrm{~Hz}$.

Therefore there is a need for investigating different frequency control strategies supplied by VSWTs, especially during island operation. Previous publications have proposed increase in the use of different frequency support actions by controlling the output power of a VSWT. The use of pitch or control strategies alternating around the optimum speed of the maximum power point to reduce the power produced [2]. Temporary frequency support during short term load miss match has also been investigated using the inertia in the rotating mass through the use of additional control measures [3]. The Spanish grid code strongly suggest inertia emulation in future codes where a suitable additional $5 \%$ power could be supplied during the first $50 \mathrm{~ms}$. Thoughts of energy storage was also presented that it would be able to inject or absorb 10 $\%$ active power for at least $2 \mathrm{~s}$. It is also stated that the dead band for inertia Emulation should be $\pm 10 \mathrm{mHz}$. The Inertia Emulation should be disabled for voltages below $0.85 \mathrm{pu}$ [9].

However, studies within islanded operation are still needed to evaluate the frequency support strategies. Island operation of wind turbines is at this moment not required by grid codes. However, with the share of generation capacity from wind farms (WFs), especially in islanded power systems, it is not feasible to disregard the frequency support that can be provided by the WFs. Different rates of WPR has been discussed but usually with the new capacity added to the previously existing production thus not reducing the effect on the frequency nadir by an increase of wind power penetration (WPP) [5],[7],[8].

The WPR can vary greatly during a future islanded operation of a grid with frequency controlled VSWT. Therefore different support strategies for load mismatch needs to be evaluated. A study related to islanded systems with frequency dependent loads subjected to large wind power penetrations is also needed. The aspect of frequency derivative needs to be used in order to compare the different strategies.

The paper is structured in a short initial review of the frequency support strategies in section II. This is then 
followed by a modeling part in section III that describes the parts taken into consideration within the modeling of a small test system. Chapter IV then presents the results of two different test sessions, one with a $20 \%$ WPR and one utilizing a $50 \%$ WPR. An adaption to the presented strategies is presented and evaluated in both of the test sessions. Special attention is given to the frequency derivatives for the different cases. Furthermore, the response of a frequency dependent load is evaluated for the two test sessions. Concluding the paper is a discussion regarding the results and some recommendations for future work.

\section{FREQUENCY SUPPORT STRATEGIES FOR VSWT'S}

\section{A. Inertia Emulation Support}

In order to provide a reduction in frequency change rate and thus reduce the temporary minimum frequency of a power system, inertia emulation can be added to the control system of the VSWTs. The inertial control signal $P_{\text {extra }}$ is based on [3],[4],[6]:

$$
P_{\text {extra }}=2 K H \omega_{s y s} \frac{d \omega_{s y s}}{d t}
$$

where $P_{\text {extra }}$ is the additional power extracted from the rotational energy, $\omega_{\text {sys }}$ is the system frequency and $H$ is the emulated inertia. However, the constant $K$ has been added to be able to adjust the level of inertia support.

\section{B. Instant Power Support}

For the sake of reducing the initial frequency drop, another method proposed by [6] is also implemented to show its performance during the initial stages of the load increase. An extra signal is the added on top of the power reference prior to the load disturbance to extract the rotational energy in accordance with a pre-defined pattern similar to Figure 1,

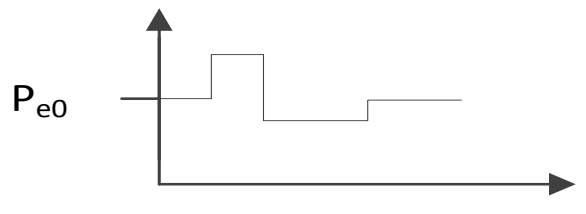

Figure 1. Instant inertia and its pre-defined pattern.

where $\mathrm{P}_{\mathrm{e} 0}$ is the pre-fault value of the maximum power point tracker. The $P_{\text {extra }}$ is then added as a deceleration area to extract energy from the rotation and a re-acceleration area that are pre-defined to how much of the rotational energy should be extracted.

\section{WIND-HYDRO SYSTEM MODELING}

Figure 2 shows the test system used to analyze primary frequency control of a wind - hydro system. Specifically, the following factors that affect system frequency response are evaluated:
1. The effect of wind power penetration level

2. Load frequency dependence

3. Two WT frequency support strategies

4. The interaction between the hydro and wind system.

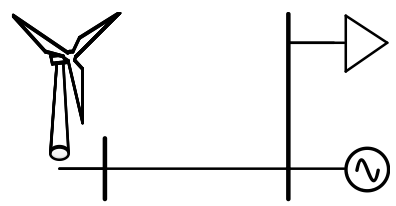

Figure 2. The analyzed power system.

The hydro generator model is adopted (since it has a slow and a less preferable initial behavior [10]) and the basic VSWT-model is adopted from [6] connected as presented in Figure 3. To investigate the effect of a frequency dependent load, a load model is implemented based on [11]. The active load demand is represented as:

$P_{\text {load }, p u}=\left(\frac{V}{V_{0}}\right)^{\alpha_{1}} \frac{1}{1+s T_{p}}\left[\left(\frac{V}{V_{0}}\right)^{\alpha_{2}-\alpha_{1}}\left(1+\frac{\beta}{100} \Delta f\right)\right]$ (2)

where $V_{0}$ is the initial load bus voltage, $V$ the actual voltage, $\beta$ the frequency characteristics coefficient for an active power load, $\alpha_{1}$ and $\alpha_{2}$ are the voltage characteristics of the load and $T_{p}$ is the time constant for the active load. The voltage is assumed to be unchanged. The parameters are available in Appendix.

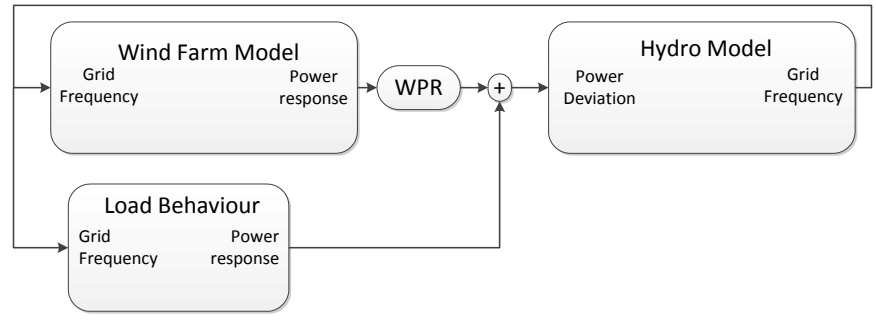

Figure 3. Schematic overview of the modeling of the test power system.

\section{SimUlation AND DATA DESCRIPTION}

\section{A. Case studies}

Instant Power Support and Inertia Emulation Support is then subjected to a base case of 20 and $50 \%$ WPR, a rotation of $0.9 \mathrm{pu}$ at a constant wind speed of $7.5 \mathrm{~m} / \mathrm{s}$ at this time the WT output power is $0.3 \mathrm{pu}$. Data on generators can be found in [6] and [10]. A load step increase of $0.1 \mathrm{pu}$ is simulated at 0 s. Table I shows five cases are presented with $20 \%$ or $50 \%$ WPR, except for one reference case using $100 \%$ hydro power production, are to be evaluated. A frequency change factor of $\beta=1$ is used (see (2)). 
TABLE I THE FIVE SIMULATED CASES AND THEIR DESCRIPTIONS

\begin{tabular}{|c|l|}
\hline Case & Description \\
\hline$\# \mathbf{1}$ & $100 \%$ Hydro \\
\hline $\mathbf{2}$ & $\mathrm{X} \%$ WPR WT without frequency support \\
\hline $\mathbf{\# 3}$ & $\mathrm{X} \%$ WPR WT with Instant Power Support \\
\hline$\# \mathbf{4}$ & $\begin{array}{l}\mathrm{X} \% \text { WPR WT with Inertia Emulation } \\
\text { Support, K=1 }\end{array}$ \\
\hline$\# \mathbf{5}$ & $\begin{array}{l}\mathrm{X} \% \text { WPR WT with increased Inertia } \\
\text { Emulation Support, K=3 }\end{array}$ \\
\hline
\end{tabular}

$B$. The effect of different WT frequency support strategies for $20 \% W P R$

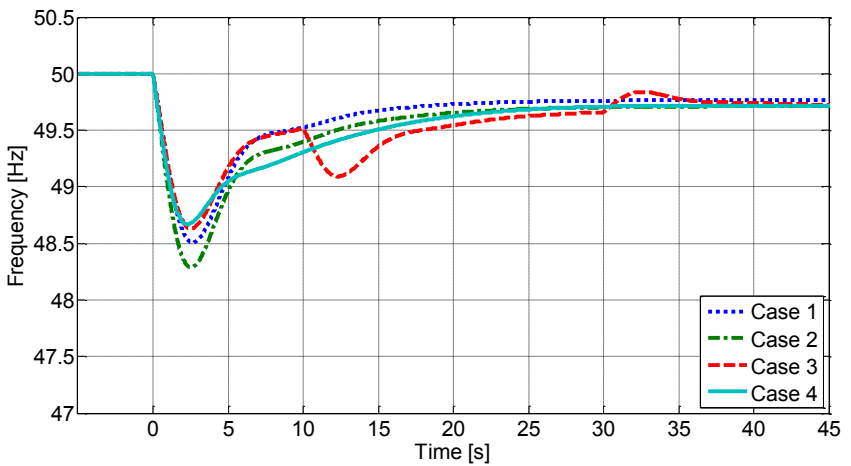

Figure 4. The frequency nadir for the simulated cases in accordance with Table I with a WPR of $20 \%$.

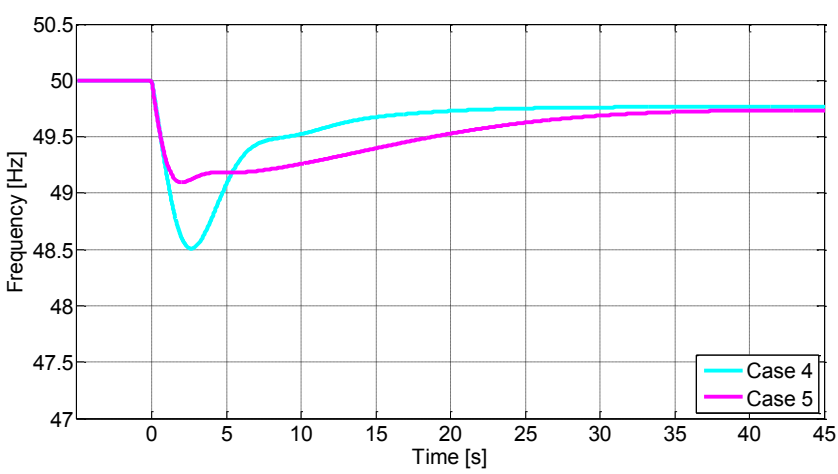

Figure 5. Frequency nadir of the presented adoption of inertia emulation compared to the original case.

The temporary minimum frequency (TMF) of each case is summarized in Table II utilizing a $\beta=1$. It can be seen that Case \#2 has the worst nadir presented, followed by the total hydro based scenario (Case \#1). In scenario number 3 and 4 the interaction from the WT can be noted to reduce the drop in overall frequency. However, the re-acceleration of the rotor is more apparent in Case \#3. Furthermore, Case \#3 disconnects the speed controller during the time when the frequency support is active and at the time of its reconnection, at $\mathrm{t}=30 \mathrm{~s}$, a mismatch in speed and speed reference can be observed. This creates a small burst of power as the speed of the turbine is reduced.

To increase the response during the initial second a constant is introduced and evaluated, shown in (1). Case \#5 is corresponding to equation with a $K=3$, Case \#4 is the earlier presented equation is according to equation, $K=1$. The resulting change in frequency nadir is presented in Figure 5.

The resulting change due to the increased power output of the added constant to the equation results in a change in TMF but it needs to be evaluated towards the need of a quick return to the steady state frequency. TMF values for the cases in Figure 5 are presented in Table II.

TABLE II. THE INTERACTION BETWEEN THE FREQUENCY DEPENDENT LOAD PARAMETER BETA AND THE TEMPORARY MINIMUM FREOUENCYOF THE FIVE ANALYZED CASES FOR A WPR OF $20 \%$.

\begin{tabular}{|l|l|l|l|}
\hline Case & $\begin{array}{l}\text { TMF }[\mathbf{H z}] \\
\boldsymbol{\beta = 0}\end{array}$ & $\begin{array}{l}\text { TMF }[\mathrm{Hz}] \\
\boldsymbol{\beta = 1}\end{array}$ & $\begin{array}{l}\text { TMF }[\mathbf{H z}] \\
\boldsymbol{\beta}=\mathbf{6}\end{array}$ \\
\hline$\# \mathbf{1}$ & 48.31 & 48.51 & 49.07 \\
\hline$\# \mathbf{2}$ & 48.02 & 48.29 & 49.00 \\
\hline$\# \mathbf{3}$ & 48.41 & 48.63 & 49.20 \\
\hline$\# \mathbf{4}$ & 48.50 & 48.67 & 49.15 \\
\hline$\# \mathbf{5}$ & 49.02 & 49.10 & 49.36 \\
\hline
\end{tabular}

The performance of the cases during the initial frequency dip for the first seconds is presented below.

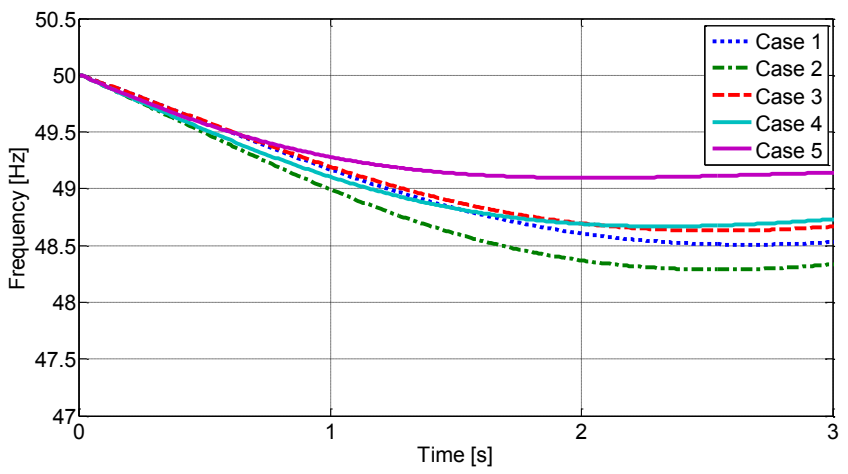

Figure 6. A enhanced view showing the different derivatives of the frequency nadir of the simulated cases in accordance with Table I for a WPR of $20 \%$.

In Figure 6 it can be observed that Case \#3 has a lower derivative than the other cases due to its rapid increase of power output after the frequency deviation is created. This shows a need for a fast response and thus to utilize the quick control of the power electronics in an improved manner. Case \#5 is a clear improvement in this sense compared to Case \#4. In the current situation (see section III) only 0.3 pu power is extracted from the WT. Thus, there is a lot of capacity of the WT system to deliver extra power from the rotational energy. One can therefore relate the inertia response depending on the power output and rating of the VSWT and its power electronics.

The different cases present different ways of producing the extra active power during Test session 1 and are presented in Figure 7. It is important to consider the interaction of the WPR in Figure 3 as a factor for this case being 0.2 multiplied to the extra power output from the wind farm. Thus, not all of the presented power will influence the frequency but only $20 \%$ of it. 


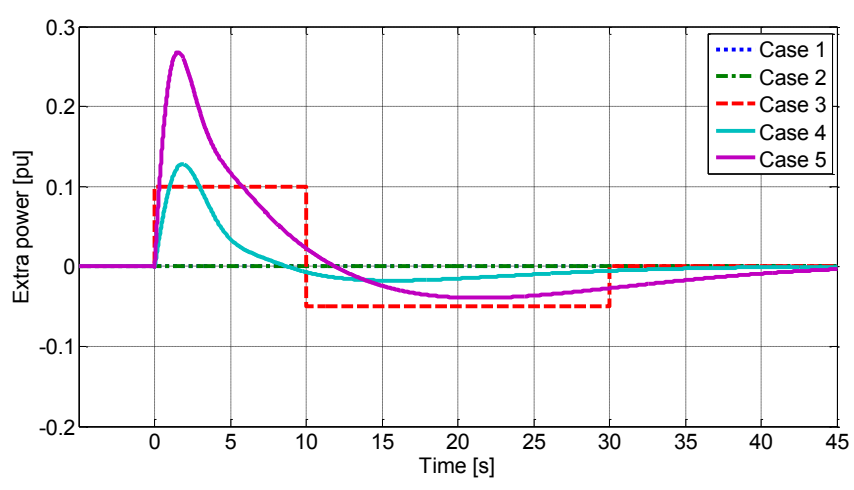

Figure 7. Power response from the various cases during a WPR of $20 \%$.

The difference between the inertia emulated values can be seen as a higher but slower transition in Case \#5 compared to Case \#4. The abrupt change in power reference in Case \#3 can also be observed which gives a complete change in response seen from the hydro unit that at this time experiences a new dip. However, this time without the support from the WT. This results in the second dip seen in Figure 4. The impact this would have on a higher WPR is presented in subsection D. As we extract rotational energy from the WT the rotor will slow down depending on the strategy used.

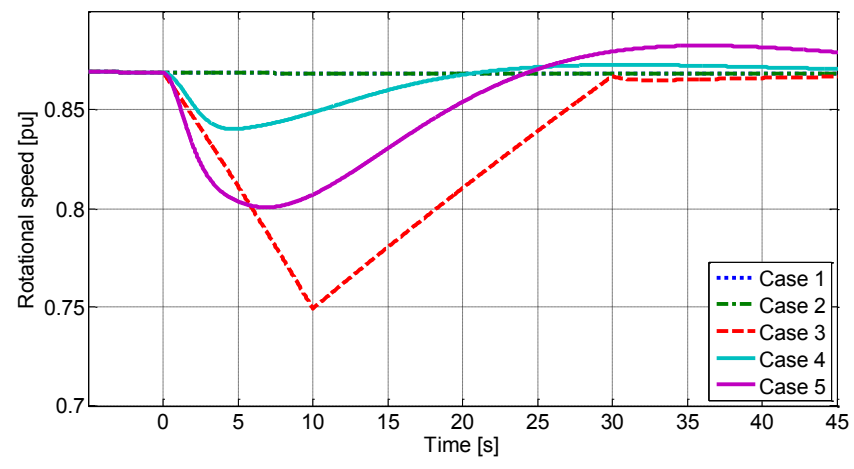

Figure 8. Response on the rotational speed of the VSWT during the different frequency support strategies during a WPR of $20 \%$.

Case \#3 presents its de-acceleration and acceleration areas and since Case \#5 extracts the most energy compared to Case \#4 a larger decrease in speed can be observed. The mismatch in speed reference can also be seen at $30 \mathrm{~s}$ for Case \#3. None of the cases violate the minimum speed of the turbine of $0.7 \mathrm{pu}$.

\section{Load frequency dependence}

Considering the result of the frequency dependent load and its interaction during the frequency dip is presented in Figure 9.

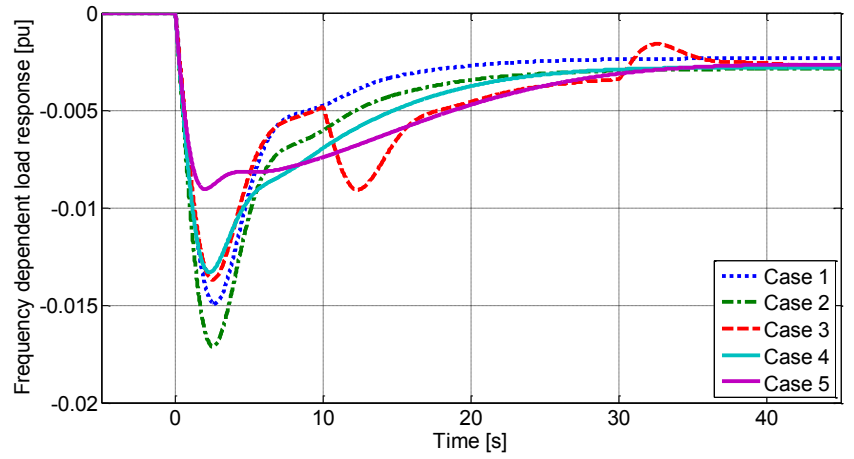

Figure 9. The response from the dynamic load model implemented and its interaction during the diffeent cases wit a WPR of $20 \%$.

It can be seen that the frequency dependence of the load is decreasing the power demand as the frequency reduces in the overall system. The frequency nadir is slightly improved compared to the case without the frequency dependent load. [11] States that the evaluated value of the frequency characteristics coefficient ( $\beta$ in (2)) can vary between $0-6$. The most common case being $\beta=1$ this is therefore used as a base for all simulations. The case of $\beta=6$ is also evaluated for the different WPR and the results shown in Table II as well as in Figure 10 in order to show its impact on the TMF.

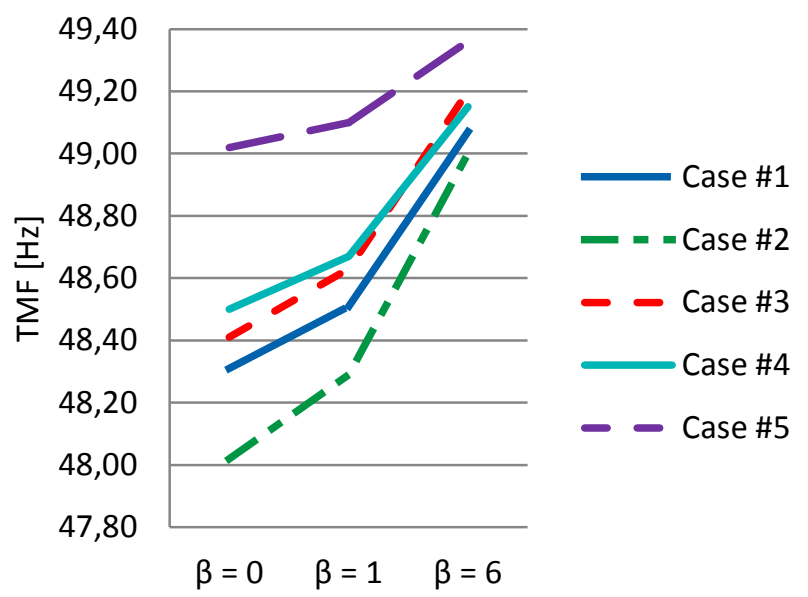

Figure 10. The interaction between the frequency dependent load parameter $\beta$ and the temporary minimum frequency of the analyzed cases.

It can be seen from that Case $\# 2$ has most to gain from the interaction from the load since the frequency change causes the reduction of power demand. The support from the WT in Case \#3 does not depend on the actual frequency change and does therefore perform better than the inertia emulated control strategy represented by Case $\# 4$ when $\beta=6$. Case $\# 5$ however reacts more to the frequency change and preforms in the best way of the evaluated cases.

\section{$D$. The effect of increasing $W P R$}

Here the impact of an increased WPR of $50 \%$ is evaluated. The axes are fixed to those of the previous sessions in order to allow for the possibility to compare the different frequency nadirs. Similarly to the first test session the system is 
subjected to a load step increase of $0.1 \mathrm{pu}$ at $0 \mathrm{~s}$ and a similar case structure is compared and evaluated.

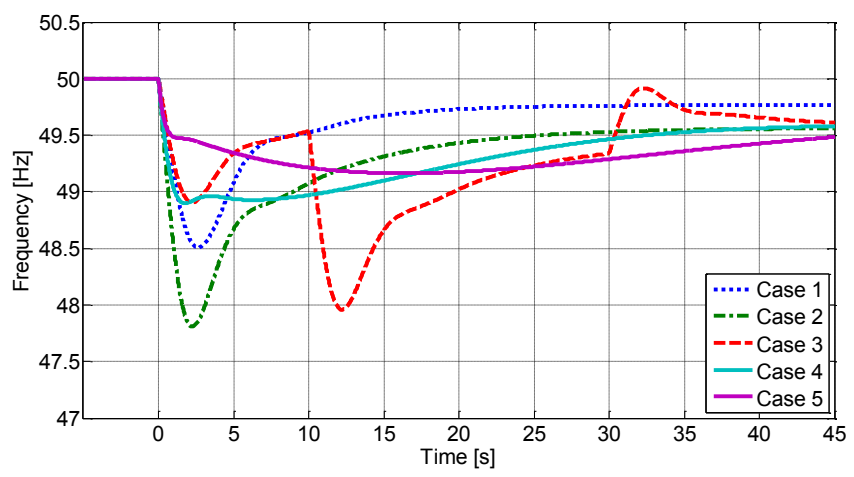

Figure 11. The frequency nadir for the simulated cases in accordance with Table I with a WPR of $50 \%$.

As expected from the previous tests the secondary dip of Case \#3 is much larger here mainly due to the larger amount of mass that has to be reaccelerated as well as a smaller amount of inertia of the hydro system reacting to this second change. The response for Case \#1 and \#2 shows a level of complexity when comparing the results. Both being hydro but in order to reduce the size of the hydro unit also the permanent droop is increased. This gives a difference in the steady state frequency deviation between Case \#1 and the other four test cases, in accordance with equation 4.

$$
\Delta f=\frac{\Delta P}{D+\frac{1}{R}}
$$

Where, $\Delta f$ is the frequency deviation in steady state, $D$ is the load damping constant, $\Delta P$ is the load change and $R$ the effective speed droop.

TABLE III. THE INTERACTION BETWEEN THE FREQUENCY DEPENDENT LOAD PARAMETER BETA AND THE TEMPORARY MINIMUM FREQUENCY OF THE FIVE TESTED CASES.

\begin{tabular}{|l|l|l|l|}
\hline Case & $\begin{array}{l}\text { TMF [Hz] } \\
\boldsymbol{\beta}=\mathbf{0}\end{array}$ & $\begin{array}{l}\text { TMF [Hz] } \\
\boldsymbol{\beta}=\mathbf{1}\end{array}$ & $\begin{array}{l}\text { TMF [Hz] } \\
\boldsymbol{\beta}=\mathbf{6}\end{array}$ \\
\hline$\# \mathbf{1}$ & 48,31 & 48,51 & 49,07 \\
\hline$\# \mathbf{2}$ & 47,33 & 47,81 & 48,87 \\
\hline $\mathbf{\#}$ & 47,61 & 47,96 & 48,83 \\
\hline$\# \mathbf{4}$ & 48,78 & 48,90 & 49,27 \\
\hline $\mathbf{\# 5}$ & 49,10 & 49,16 & 49,41 \\
\hline
\end{tabular}

Even though the initial response is improved for Case \#4 and \#5 a larger contribution during the first second from case \#3 is utilized. An adaption of the characteristics of the extra power support might improve the performance by the inertia emulated cases.

\section{E. Contribution from VSWT during $50 \% \mathrm{WPR}$}

Compared to the previous test session the response from the WT creates a larger impact due to a WPR of $50 \%$ compared to $20 \%$ previously. The response provided by the WT during the load deviations are presented in Figure 12.

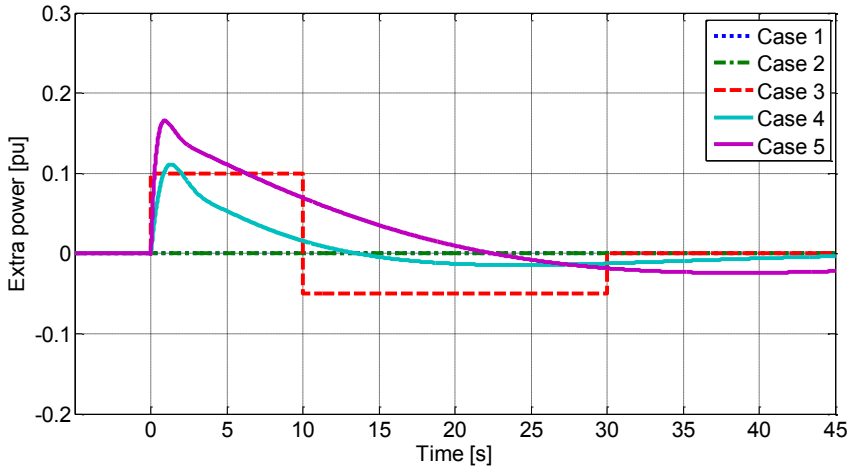

Figure 12. Power response from the various cases during a WPR of $50 \%$.

Compared to the previous test session a lower interaction can be observed from the individual turbines due to the increased power input in total from the temporary support in case \#4 and \#5. However, the steady state frequency droop create some problems for the control system in the two cases creating a slow response. This would however be reduced by secondary frequency control.

\section{$F$. Interaction between wind turbine and hydro unit}

The support from the WT has a great effect on the hydro unit in the power system, the main support is provided at the time when the hydro output power change is negative. The interaction between the WT and Hydro unit during Case \#4 is shown below and compared to Case \#1.

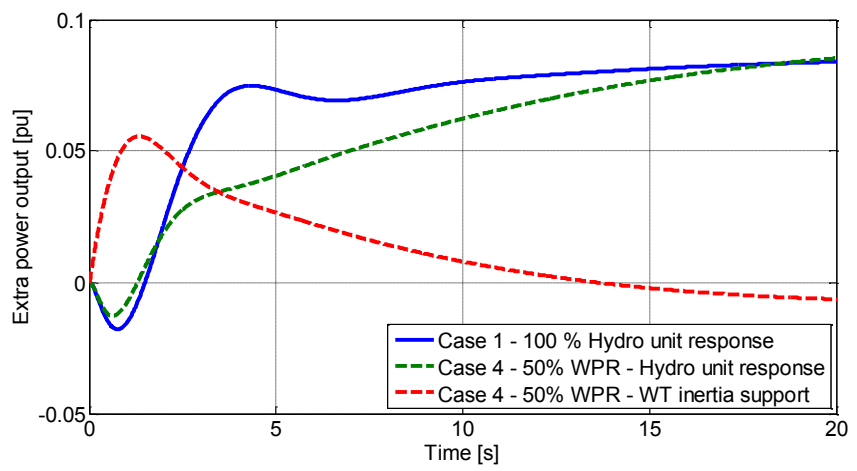

Figure 13. The interaction between the hydro and wind turbine durig the disturbance and a WPR of $50 \%$ compared to Case \#1.

It can be shown that the support from the WT affects that of the hydro at this time.

One benefit of the Case \#3 structure is that the action of the WT is known for a longer period and could thus, in an already islanded operation, be sent as a signal to prepare the hydro unit mainly for the re-acceleration period of the turbine. Furthermore, Case \#3 had several un-wanted characteristics in its profile these are improved by reducing the shift between de-acceleration and re-acceleration areas. This has been adapted and the result is presented below as Case \#6. 


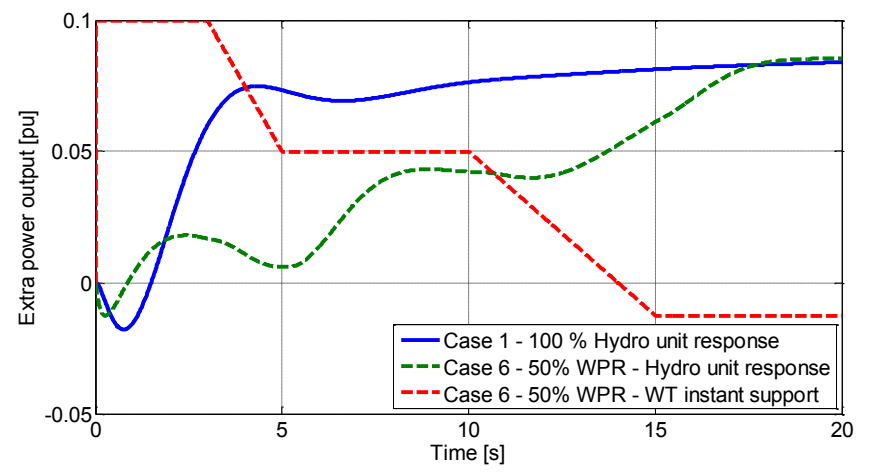

Figure 14. Adapted instant power suport with extra error signal to the hydro unit for a WPR of $50 \%$ compared to the hydro response of Case \#1.

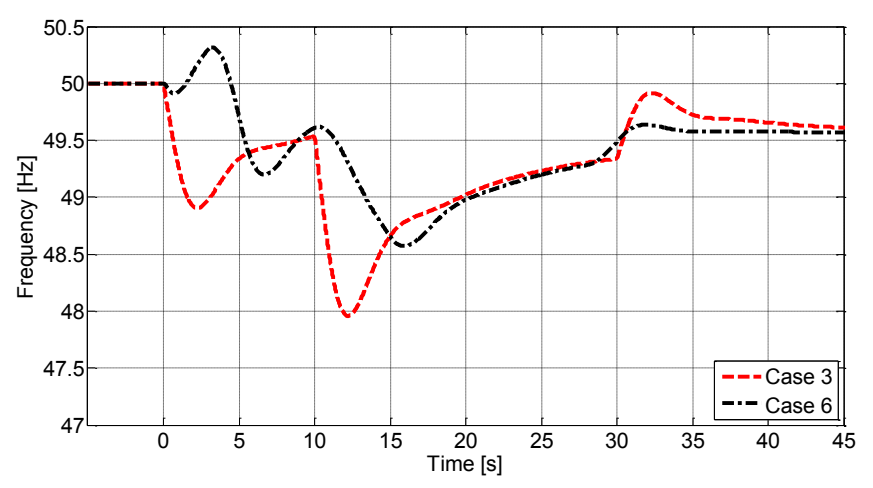

Figure 15. Frequency nadir of the two instant power strategies.

Case \#6 is an improvement compared to Case \#3 and the slopes attached to the frequency support profile shows a clear improvement to the frequency nadir.

The frequency dependence of loads transitioning to or operating in weak power systems should be taken into consideration. However, for stronger networks the affect would be so smaller due to the larger inertia of the system.

\section{CONCLUSIONS}

The improvement of the frequency nadir by $1 \mathrm{~Hz}$ from Case \#2 to Case \#5 has been presented in the case of $20 \%$ WPR considering a non-frequency dependent load. To extract extra energy quickly is a benefit of a VSWT and the inertia emulation support should also be designed in accordance with these possibilities.

The frequency dependence of loads transitioning to or operating in weak power systems should be taken into consideration. However, for stronger networks the affect would be so smaller due to the larger inertia of the system.

Future VSWT will utilize the inertia emulation strategies; however it is of great interest to investigate how this energy should be extracted. The extra active power supported needs to be activated as soon as possible but still depend on the frequency and the outlook of the system. Even if Case \#3 has its downsides it also provides the knowledge of what will happen for the $30 \mathrm{~s}$ while it's active. A coordinated control between the hydro and wind turbine in this case could solve the issues of secondary dips especially for Case \#3 where the behavior of the wind turbine is predefined and could thus be known for the hydro governor.

The interaction in islanded systems between the different production units in a smart grid could improve the behavior during a load miss match or when the transition to islanded operation occurs. However, this needs to be investigated further.

The behavior of the load demand due to supply voltage should be evaluated since a temporary voltage reduction across the load could improve the frequency behavior further.

\section{APPENDIX}

Load model: $V_{0}=1, V=1,0<\beta<6, T_{p}=51 \mathrm{~ms}, \alpha_{1}=2$ and $\alpha_{2}=1$.

Inertia emulation: $\mathrm{H}=5.19 * 3$ (to get equal energy output during de-acceleration area between case \#3 and \#4 for $20 \%$ WPR), $\mathrm{K}=1$ or 3 .

Instant power, $\mathrm{t}_{\mathrm{acc}}=20 \mathrm{~s}, \mathrm{t}_{\mathrm{de}-\mathrm{acc}}=10 \mathrm{~s}, P_{\text {extra }}=0.1 \mathrm{pu}$ during $t_{\text {de-acc }}$ and 0.05 during $t_{a c c}$

\section{REFERENCES}

[1] Ramtharan, G.; Ekanayake, J.B.; Jenkins, N.; , "Frequency support from doubly fed induction generator wind turbines," Renewable Power Generation, IET, vol.1, no.1, pp.3-9, March 2007

[2] Tarnowski, G.C.; Kjær, P.C.; Dalsgaard, S.; Nyborg, A.; , "Regulation and frequency response service capability of modern wind power plants," Power and Energy Society General Meeting, 2010 IEEE , vol., no., pp.1-8, 25-29 July 2010

[3] Ekanayake, J.; Jenkins, N.; , "Comparison of the response of doubly fed and fixed-speed induction generator wind turbines to changes in network frequency," Energy Conversion, IEEE Transactions on , vol.19, no.4, pp. 800- 802, Dec. 2004

[4] Yuan-zhang Sun; Zhao-sui Zhang; Guo-jie Li; Jin Lin; , "Review on frequency control of power systems with wind power penetration," Power System Technology (POWERCON), 2010 International Conference on, vol., no., pp.1-8, 24-28 Oct. 2010

[5] Erlich, I.; Rensch, K.; Shewarega, F.; , "Impact of large wind power generation on frequency stability," Power Engineering Society General Meeting, 2006.

[6] Ullah, N.R.; Thiringer, T.; Karlsson, D.; , "Temporary Primary Frequency Control Support by Variable Speed Wind TurbinesPotential and Applications," Power Systems, IEEE Transactions on , vol.23, no.2, pp.601-612, May 2008

[7] C., Sørensen, P. E., \& Østergaard, J. "Study on variable speed wind turbines capability for frequency response" in:EWEC 2009 Scientific proceedings. EWEC, pp. 190-193

[8] Duval, J.; Meyer, B. , "Frequency behavior of grid with high penetration rate of wind generation," PowerTech, 2009 IEEE Bucharest, vol., no., pp.1-6, June 282009

[9] Altın, M.; Göksu, O.; Teodorescu, R.; Rodriguez, P.; Jensen, B.-B.; Helle, L.; , "Overview of recent grid codes for wind power integration," Optimization of Electrical and Electronic Equipment (OPTIM), 2010 12th International Conference on , vol., no., pp.1152-1160, 20-22 May 2010

[10] Kundur, P. "Power System Stability and Control", McGraw-Hill 1994.

[11] Yamashita, K.; Asada, M.; Yoshimura, K.; , "A development of dynamic load model parameter derivation method," Power \& Energy Society General Meeting, 2009. PES '09. IEEE , vol., no., pp.1-8, 26-30 July 2009 